\section{Assessment of the Apple iPad as a low-vision reading aid}

E Morrice $^{1,2}$, AP Johnson 1,2,3, J-A Marinier ${ }^{2,4}$ and W Wittich ${ }^{1,2,3,4}$

impairments. ${ }^{1}$ With the percentage of adults above the age of 60 rising, an increased number of people affected by visual impairments should be expected. ${ }^{2}$ Difficulty in reading is the most frequent complaint made by individuals with a visual impairment, and is the main cause of being referred to rehabilitation services. ${ }^{3-6}$ Rehabilitation interventions for reading difficulties are often linked to magnification, and can fall into two main categories: low-tech with the use of tools such as loupes, and high-tech through the use of electronic magnification such as closed-circuit televisions or head-mounted devices. ${ }^{7-8}$ The recent development of portable electronic devices that can be used for reading, such as the Apple iPad, offer an alternative magnification tool to those that are traditionally used in rehabilitation. However, there is little evidence to show how effective portable electronic reading devices are as low-vision aids or how they compare against existing magnification aids.

Previous researchers have shown that with magnification, reading performance (as measured by reading speed) can be improved by up to $200 \% .4,9$ The most common types are hand-held and video magnifiers, such as the close-circuit television (CCTV).

Typically, CCTVs have higher levels of magnification in comparison with other magnification devices. ${ }^{10}$ When magnified and displayed on a larger screen this increases reading speed. ${ }^{11-12}$

In addition to hand-held and video magnifiers, rehabilitation agencies and clinicians have recently been recommending electronic portable reading devices—such as the iPad-as a low-vision reading aid. Electronic tablet readers combine the portability of hand-held magnifiers with the high-resolution displays of CCTVs, and have a wide variety of free and/or for-purchase downloadable applications, for example, VisionAssist, an app that increases magnification and adjusts contrast polarity. As such, tablet readers are believed to be a
${ }^{1}$ Department of Psychology, Concordia University, Montréal, Quebec, Canada

${ }^{2}$ Centre de recherche interdisciplinaire en réadaptation du Montréal métropolitain, Montréal, Quebec, Canada

${ }^{3}$ Centre de réadaptation MAB-Mackay du CIUSSS du Centre-Ouest-de-l'Îlede-Montréal, Montréal, Quebec, Canada

${ }^{4}$ School of Optometry, University of Montreal, Montréal, Quebec, Canada

Correspondence: E Morrice, Department of Psychology, Concordia University, 7141 Rue Sherbrooke Ouest, Montréal, Quebec H4B 1R6, Canada

Tel: +514 8482424

ext. 2212;

Fax: +514 8484545 E-mail: elliott.morrice@ mail.concordia.ca

Received: 19 April 2016 Accepted in revised form: 27 November 2016

Published online:

3 February 2017 
useful tool for those with low vision. A recent online survey of people with visual impairments found that nearly half of their respondents (48\%) already owned and were using a tablet computer as a low-vision aid. ${ }^{13}$ However, there is little empirical research to support these recommendations, with most endorsements coming from anecdotal evidence made by rehabilitation specialists. ${ }^{14}$ Gill et al ${ }^{15}$ compared the reading speeds of participants using the Apple iPad, the Sony e-reader, and plain text presented on a sheet of paper. The researchers found that participants consistently read faster on the iPad with larger text sizes and rated the iPad as having the best clarity. ${ }^{15}$ Roth et al directly explored reading performance across three conditions (newspaper, a printout of a news article, and a news article on an iPad) in low-vision participants. ${ }^{16}$ Measuring reading speed in words per minute, Roth et al found that individuals had faster reading speeds when reading from the iPad, compared to when reading from the newspaper or a printed page from an internet website. ${ }^{16}$ Other benefits of the iPad include apps to present text at high contrast, as single scrolling lines of text, and present text in dynamic formats, all of which have been shown to increase reading speed and ability. ${ }^{17-20}$

The purpose of the present study was to compare the reading performance (as assessed by reading speed) of participants with low vision, using the iPad, the CCTV, and the individual's home reading device or technique. We utilized standardized texts that had the same level of difficulty across all conditions, and participants were tested in their dominant language (English or French). Each text was followed by a multiple-choice comprehension question to ensure that the participants understood the content of the text they read. We included a questionnaire to assess language, background, and reading habits before and after onset of low vision. We hypothesized that participants would have faster reading speeds using the iPad as compared to the CCTV or their home device.

\section{Materials and methods}

The research protocol was approved by the research ethics board of the Centre for Interdisciplinary Research in Rehabilitation of Greater Montreal, in accordance with the Canadian Tri-Council Policy Statement of ethical conduct for research involving humans.

\section{Participants}

100 participants, clinically diagnosed with low vision, were recruited from the client list of the MAB-Mackay Rehabilitation Centre. Participants were required to have a visual acuity better than $6 / 90$, but worse than $6 / 24$ in the better eye with best standard correction, as measured by the ETDRS chart, or qualify for low-vision rehabilitation in the province of Quebec. ${ }^{21}$ See Table 1 for a breakdown of diagnoses and standard demographics such as gender, age, education level, diagnosis, and visual acuity.

\section{Measures}

Montreal cognitive assessment-blind The Montreal cognitive assessment (MoCA) screens for mild cognitive impairment in adults with functional vision $\left(\mathrm{MoCA}^{22}\right)$, and has been modified and validated to allow for the

Table 1 Participant demographics

\begin{tabular}{|c|c|}
\hline Demographics & $\mathrm{N}$ \\
\hline \multicolumn{2}{|l|}{ Total survey respondents } \\
\hline Male/Female & $39 / 61$ \\
\hline \multicolumn{2}{|l|}{ Impairment (in terms of visual acuity) ${ }^{\mathrm{a}}$} \\
\hline $6 / 9$ to $6 / 60(\log M a r 0.18-1.00)$ & 77 \\
\hline $6 / 61$ to $6 / 120(\log M a r 1.01-1.30)$ & 19 \\
\hline $6 / 121$ or worse (logMar 1.31 or worse) & 3 \\
\hline \multicolumn{2}{|l|}{ Primary diagnosis } \\
\hline Macular degeneration & 57 \\
\hline Diabetic retinopathy & 6 \\
\hline Glaucoma & 6 \\
\hline Other & 25 \\
\hline Unknown & 6 \\
\hline \multicolumn{2}{|l|}{ Age } \\
\hline Less than 50 years & 9 \\
\hline $50-59$ years & 7 \\
\hline $60-69$ years & 13 \\
\hline $70-79$ years & 18 \\
\hline $80-89$ years & 40 \\
\hline 90 years or more & 13 \\
\hline \multicolumn{2}{|l|}{ Language } \\
\hline French & 16 \\
\hline English & 84 \\
\hline \multicolumn{2}{|l|}{ Highest level of education } \\
\hline Primary & 4 \\
\hline Secondary & 40 \\
\hline Post-secondary & 56 \\
\hline \multicolumn{2}{|l|}{ Self-reported reading ability ${ }^{\mathrm{b}}$} \\
\hline No ability & 0 \\
\hline Elementary & 4 \\
\hline Moderate & 4 \\
\hline Very good & 15 \\
\hline Fluent & 75 \\
\hline
\end{tabular}

a'One participant's acuity was listed only as 'Hand Motion' and therefore

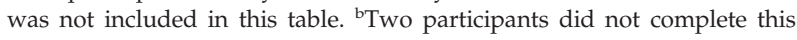
question and therefore are not included in this table. 
screening of cognitive impairment in adults with low or no vision $\left(\mathrm{MoCA}-\mathrm{B}^{23}\right)$.

The visual function index This assesses the degree of perceived difficulty individuals experience completing a number of daily tasks related to vision. ${ }^{24}$ The visual function index (VF-14) consists of fourteen questions, including three questions that assess reading. Participants rated the level of difficulty they had with the task, with corrective lenses, from 0 (unable to do the activity) to 4 (no difficulty).

Demographics and reading questionnaire This questionnaire consisted of 23 multiple-choice questions, measuring socio-demographic information and language background (eg, mother tongue, language proficiency). It also assessed self-reported proficiency in reading ( $1=$ no ability, $5=$ fluent ability), and reading habits before and after onset of low vision (eg, frequency, enjoyment, type of reading). Participants were also asked if they had previous experience with the iPad or CCTV.

\section{Materials}

Closed-circuit television We used the ClearView+model (Optelec, Longueuil, QC, Canada), which has a 22-inch thin film transistor screen (flicker-free panel).

Apple iPad We used an Apple iPad Air (2013 model, 16 GB) with a 9.7 inch (diagonal) backlit LED rectangular screen. The brightness of the iPad was maintained at the maximum level, and the device was held still throughout the trials.

Home magnification The home magnification device was any visual aid that the participants most commonly used when reading long text (eg, hand-held magnifier). If their home device was the Apple iPad or the CCTV, then participants read using the iPad or CCTV we provided. For any other home device participants used a visual aid that they brought to the study.

The international reading speed texts The International Reading Speed Texts (IReST ${ }^{25}$ ) are standardized reading materials used to measure reading speed under naturalistic conditions (ie, newspaper print). In our study, participants read these texts in either English or French, they are homogeneous and comparable for repeated measurements within and between languages. The order in which participants read the text was pseudorandomized across conditions. Based on the normative reading rates provided by Trauzettel-Klosinski and the IReST study group we selected Texts $1,2,4$, and 8 as our test texts. ${ }^{25}$ These texts have average reading speeds that do not differ by more than 10 words per minute, and are thus considered comparable. In addition, a fifth text (Text 7) was chosen as a practice text (as recommended by the IReST study group).

\section{Procedures}

Upon arrival, participants were instructed on the content and procedure of the study and informed consent was obtained. The participants completed the MoCA-B, and then read the IReST texts in the four reading conditions (baseline, iPad, CCTV, home magnifier), with the order pseudo-randomized to reduce practice or fatigue effects. For the iPad and CCTV condition, the participants were given instructions on how to use the device with a practice text, and could adjust the contrast and magnification settings to what they felt would be ideal for reading. The distance between the participant's eye and the reading device was measured for each condition.

The size of the text was also recorded for each condition. In the CCTV condition the first letter of the text, either an uppercase A, I, O, or T, depending on which text the participant read, was measured after the participant chose their preferred degree of magnification. This information was then converted into degrees of visual angle, to compare the text sizes across all conditions.

For all reading conditions, the participants were required to read the text aloud, while the researcher recorded completion time as well as errors using a stopwatch (rounded to the nearest $1 / 10^{\text {th }}$ of a second). An error was any word that was skipped or mispronounced by the participant. Participants then completed a multiple-choice comprehension question about the content of the reading. In addition, the contrast settings, polarity (ie, black text on white background), and the chosen font size were recorded. If the participant was unable to read the text it was noted in their participant file. Upon completion, participants completed the VF-14, and the Demographics and Reading Questionnaire.

\section{Data analysis}

Prior to running the analyses, all variables of interest were assessed for normality. We used the Kolmogorov-

Smirnov test for normality, with all variables of interest having a $\mathrm{k}-\mathrm{s}$ value $<1$, and significance level of the test of $>0.05$.

As we were interested in the magnitude of the effect (ie, increase in reading rate) caused by the magnification of text by each device in comparison to baseline, we analyzed the difference scores (in wpm) using a two-sample dependent (or paired) $t$-test (with HolmBonferonni correction for multiple comparisons) on the word-per-minute data. We also report 95\% confidence 
intervals around the mean difference as a measure of the margin of uncertainty around the estimated difference between the two means, and bias-corrected Hedge's $g\left(g^{*}\right)^{26}$ as an effect size measure.

\section{Results}

\section{Descriptive statistics}

To test whether our participants were a representative sample of a visually impaired population that report having difficulties with reading, we analyzed the readingrelated questions on the VF-14 questionnaire (ie, items 1-3). Participants reported a great deal of difficulty reading small $(M=0.54, \mathrm{SD}=0.79)$ and medium text $(M=0.76, \mathrm{SD}=1.02)$, and report less difficulty with large text $(M=2.60, \mathrm{SD}=1.46)$ when compared with small text, $t(198)=12.41, P<0.001, g^{*}=1.75, g^{*} C I$ (1.42 2.07). Thus, increasing text size using any magnification device should improve reading performance in our participants.

We were interested in reading habits before and after the onset of vision loss. A majority of our participants $(85 \%)$ reported enjoying reading before the onset of their low vision. However, only $35 \%$ reported enjoying reading after the onset of their low vision.

We also assessed participants experience with the CCTV and iPad; 59\% reported having previous experience with the CCTV, although only $35 \%$ of participants reported currently using the CCTV as their primary magnification device. Conversely, of the $28 \%$ reporting to have experience with the iPad, all were currently using the iPad. Note that in case of both the CCTV and iPad, experience was not quantified.

To ensure that participants understood the content of the texts, a multiple choice reading comprehension question was asked following each reading task. On the basis of the results, in the iPad (97\%), CCTV (97\%), home device (93\%), and baseline, that is, no magnification, conditions (95\%), the majority of participants who completed the task answered the reading comprehension question correctly. The high accuracy of participants on the reading comprehension task confirms that a majority of participants comprehended the texts, increasing the integrity of the reading rates reflecting true reading performance.

\section{Primary outcome: reading speed across devices}

To test our hypothesis that participants would have faster reading speeds when reading using the iPad compared to the other reading devices, we calculated the mean reading speeds in words per minute (wpm) across participants for the baseline condition and on each device (Table 2). During baseline, participants found reading without
Table 2 Reading speeds (in words per minute) and normalized ${ }^{\text {a }}$ reading speeds (in words per minute) for all conditions

\begin{tabular}{lccc}
\hline & $\mathrm{N}$ & Range & Mean \pm SD \\
\hline Reading Speeds (wpm) & & & \\
$\quad$ Baseline (no magnification) & 100 & $0-187.4$ & $16.5 \pm 43.4$ \\
CCTV & 100 & $0-186.6$ & $76.7 \pm 36.2$ \\
Apple iPad & 100 & $0-209.5$ & $79.5 \pm 47.4$ \\
Home magnification & 54 & $13.9-738.5$ & $97.3 \pm 97.6$ \\
& & & \\
Normalized Reading Speed (wpm) & & & \\
Baseline (no magnification) & 100 & $-9.9-0$ & $-6.9 \pm 2.8$ \\
CCTV & 100 & $14.5-186.6$ & $76.5 \pm 37.7$ \\
Apple iPad & 100 & $-8.9-9$ & $-5.4 \pm 1.8$ \\
Home magnification & 54 & $-8.2-15.9$ & $-4.8 \pm 3.4$ \\
\hline
\end{tabular}

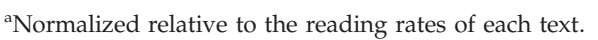

magnification extremely difficult, with most being unable to read the text, or showing slow reading speeds. A repeated-measures analysis of variance (ANOVA) was run to determine if there were significant differences in reading speed across devices. Mauchly's Test of Sphericity was significant $\left(\chi^{2}(5, N=54)=116.31\right.$, $P<0.001)$ and therefore the Greenhouse-Geisser correction was used. There was a significant difference $\left(\mathrm{F}(3,73.05)=21.01, P<0.001, \eta_{\rho}^{2}=0.28\right)$ such that all devices increased reading speed in comparison to baseline as indicated by post hoc comparisons using the Bonferroni correction: iPad $\left(M_{\text {difference }}=60.12 \mathrm{wpm}, P<0.001, \mathrm{CI}\right.$ $(43.48,76.79))$, CCTV $\left(M_{\text {difference }}=52.59 \mathrm{wpm}, P<0.001\right.$, $\mathrm{CI}(36.57,68.61))$, and home device $\left(M_{\text {difference }}=66.69\right.$ wpm, $P<0.001$, CI $(27.93,105.45))$. However, there were no significant differences in reading speed among the three low-vision device conditions. As not all participants used a home device, $n=46$ could not be included in a repeated-measures ANOVA; therefore subsequent pairwise comparisons were conducted using paired samples t-tests to get a more accurate measure of performance and effect size across each device comparison. The paired samples t-test showed participants had statistically significant increases in reading speed in comparison to the baseline when using the iPad $\left(M_{\text {difference }}=63 \mathrm{wpm}, P<0.001, \mathrm{CI}(50.49,75.57)\right.$, $\left.g^{*}=1.40, g^{*} \mathrm{CI}(1.09,1.71)\right), \operatorname{CCTV}\left(M_{\text {difference }}=60.2 \mathrm{wpm}\right.$, $P<.001$, CI $\left.(49.23,71.21), g^{*}=1.53, g^{*} \mathrm{CI}(1.21,1.84)\right)$, and home device $\left(M_{\text {difference }}=80.8\right.$ wpm, $P<0.001$, CI (58.39, $\left.103.11), g^{*}=1.2, g^{*} \mathrm{CI}(0.84,1.56)\right)$, to magnify the text. Given that individuals with AMD make up a majority of our participants, we re-ran the same analysis, but only on individuals with AMD, and found the same pattern of results, with reading speed in comparison to the baseline when using the iPad $\left(M_{\text {difference }}=55 \mathrm{wpm}, P<0.001\right.$, CI $\left.(41.67,68.37), g^{*}=1.52, g^{*} \mathrm{CI}(1.10,1.94)\right)$, CCTV $\left(M_{\text {difference }}=55 \mathrm{wpm}, P<0.001\right.$, CI $(43.31,66.05), g^{*}=1.77$, 
$\left.g^{*} \mathrm{CI}(1.34-2.21)\right)$, and home devices $\left(M_{\text {difference }}=59 \mathrm{wpm}\right.$, $\left.P<0.001, \mathrm{CI}(44.76,74.17), g^{*}=1.82, g^{*} \mathrm{CI}(1.29,2.34)\right)$.

\section{Additional analysis: font size and effect of experience with CCTV and Apple iPad}

Unlike previous studies, ${ }^{14-15}$ we allowed participants to choose the size of text that they considered best for reading. Therefore, we were interested in comparing the font size chosen by participants on both the CCTV and the iPad. Note that calculation of font size was not possible with the home magnification devices due to most being optical magnifiers. After measuring font size (in $\mathrm{mm}$ ) and distance (in $\mathrm{mm}$ ), we converted the font size on both devices into minutes of arc. Three participants were not included in the analysis due to missing distance and/or size information. We observed that with the CCTV, average text size was both large and highly variable across participants $(M=823$ arcminute, $S D=3629$, Range 28.51- 31439, 95\% CI (95.9, 1551). Conversely, iPad users chose to use a smaller text size, and showed less variability across participants $(M=130$ arcminute, SD $=96$, Range 16-565, 95\% CI $(109,149)$, trending towards a statistically significant difference $\left(M_{\text {difference }}\right.$ $=695, \mathrm{SD}_{\text {pooled }}=2567$ arcminute, $t(192)=1.885, P=0.06$, $95 \%$ CI $\left.(-32,1422), g^{*}=0.27\right)$.

We also addressed if experience with the device had an effect on reading speed. As seen in Table 3, although a majority $(55 \%)$ of participants had received CCTV training, we observed no difference in reading speeds between those with CCTV training and those without $\left(M_{\text {difference }}=1.6 \mathrm{wpm}, P=0.835\right.$, CI $(-13.3118,16.45)$, $g^{*}=0.04, g^{*}$ CI $\left.(-0.37,-0.45)\right)$. Conversely, compared to those with no experience with the iPad $(n=70)$, those that had experience with the iPad showed an increase in words read per minute $\left(M_{\text {difference }}=-30 \mathrm{wpm}, P=0.005\right.$, CI $(-50.76,-9.17), g^{*}=0.67, g^{*}$ CI $\left.(0.2,1.1)\right)$.

\section{Discussion}

The purpose of this study was to investigate whether the Apple iPad is a useful tool for those with low vision.

Table 3 Comparing reading speeds (in words per minute) when using the CCTV and Apple iPad, between individuals with and without experience on each device

\begin{tabular}{lccr}
\hline & $N$ & Range & Mean \pm SD \\
\hline CCTV & & & \\
$\quad$ No experience & 39 & $22.0-164.6$ & $78.1 \pm 32.8$ \\
$\quad$ Experience & 55 & $14.5-186.6$ & $76.5 \pm 37.7$ \\
& & & \\
Apple iPad & & & \\
$\quad$ No experience & 70 & $7.8-170.8$ & $72.8 \pm 37.9$ \\
$\quad$ Experience & 24 & $23.2-209.5$ & $102.8 \pm 59.3$ \\
\hline
\end{tabular}

Specifically, we were interested in changes in reading speed associated with the iPad compared to the CCTV and home magnification devices. We found that compared to baseline, all three device categories (iPad, CCTV, and home magnification) show similar improvements in reading speed. These results are encouraging as they indicate that individuals using the iPad read at a comparable rate to using the current 'gold standard' in low-vision rehabilitation, the CCTV. We also examined the effect of previous experience using the iPad versus previous experience using the CCTV. There were no differences in the reading rates of participants who had previous experience using the CCTV compared to the reading rates of first time CCTV users. However, there were differences ( 30 words per minute) in the reading rates of experienced iPad users compared to first time iPad users. It is also important to note that operating a CCTV for the first time may be more difficult than using an iPad for the first time. However, increased exposure to and experience with the iPad may increase reading speed with that device.

Reading is an important task of daily living that most adults enjoy, and difficulty with this task is one of the main causes of being referred to rehabilitation services. ${ }^{4-6}$ Based on the results of the reading habits assessed by our questionnaire, it was found that $91 \%$ of our participants enjoyed reading before the onset of their low-vision condition, whereas only $35 \%$ enjoyed reading after the onset of their low-vision condition. Previously, researchers have shown that use of assistive low-vision devices that magnify text improve reading speed for those with low vision (eg, Nguyen et $a l^{9}$ ). Our study has shown that the iPad perform just as well as current assistive devices such as the CCTV, but that exposure to and experience with the iPad may increase the average reading speed of those with low vision. This could have implications for participants overall reading ability and for reading enjoyment as well. In a study by Arthanat, Vroman, and Lysack, thirteen older adults were given an in-home information communication technology training program over the course of three months using the iPad. ${ }^{27}$ Although this study did not deliberately examine reading speed using the iPad, the authors examined how older adults learned to use the iPad as well as their opinions of technology use across multiple dimensions (satisfaction, creativity, encouragement, comfort, anxiety, social interactions, and opinions of self). At the end of the study, participants were given the option to receive monetary compensation for participating in the study or to retain ownership of the iPad; only one participant opted for the monetary compensation. ${ }^{27}$ Although participants reported higher levels of frustration with technology at the beginning of the study by Arthanat et al, ${ }^{27}$ by the end of the training sessions, participants reported higher 
levels of satisfaction with technology. Similar results were found when examining comfort with technology; participants were more intimidated by technology at the beginning of the training period, but results showed that by the end of the training period they were more comfortable using the iPad. Possible future directions for research in rehabilitation may examine whether training and experience using the iPad will increase reading speeds in low-vision clients.

Other studies have examined the use of the iPad as a lowvision reading aid ${ }^{15-17}$ and found that participants had higher reading speeds compared to other devices when using the iPad. The results of the present study confirm and are consistent with these findings as our participants had faster reading speeds when using the iPad compared to when they read from just a piece of paper. Going beyond this finding, our study compared the iPad to other assistive devices, and found that the iPad performed just as well as these devices. However, when experience was taken into consideration, previous exposure to the iPad was linked to increased reading speeds. This increase in reading speed due to exposure may show that more time with, or training on, the iPad may be required for these benefits to become apparent. ${ }^{27}$ It is also conceivable, however, that those with previous experience using the iPad may also have higher levels of education, income, or better visual acuity. Future studies should examine the impact of experience and/or training on the iPad, social/economic factors, and their effects on reading speed.

One of the limitations of the current study is that the measure used to assess reading comprehension may not have been challenging enough for some of the participants. As the original IReST text was at a sixthgrade reading level, the reading comprehension questions designed for the purpose of this study were also written at a sixth-grade level. Further, our aim in using the comprehension questions was to encourage participants to read the text at a speed that they could comprehend the content of the text. Future studies should include a wider and varied range of more challenging measures to assess reading performance. A second limitation is that the act of reading on the iPad and reading using the CCTV may not be directly comparable. Access to each text and its magnification through the iPad was accomplished by programming the IReST texts directly into the iBook app. Therefore, individuals could choose their desired font size directly within iBooks, and then scroll through the text with swipe commands on the touch screen. In comparison, access to the texts on the CCTV was accomplished though the traditional placement of paper under the CCTV camera, magnification through the CCTV controls, and scrolling of the text through moving the CCTV tray from side to side. This action has previously been reported to induce nausea in some users, a phenomenon that has not been reported with the iPad. ${ }^{28}$ On the contrary, a study by Walker using drifting horizontally-scrolling text on an iPad, found that the majority of participants with macular disease reported improved reading ability when the drifting text was presented at a PRL. ${ }^{29}$ Therefore, reading speed is likely, in part, dependent on the reading techniques involved. Linked to these reading techniques, it could be argued that the manual dexterity required to operate a CCTV tray for stable and continuous reading may place higher demands on the low-vision reader than simply swiping across a tactile screen to move text or turn a page; again, however, we did not observe slower reading rates in the CCTV condition, should this be the case. Future studies should therefore compare the iPad with a portable CCTV in the same context: using the camera and magnification capacities on each to assess different types of reading conducted in daily activities (eg, reading medicine bottles, newspaper).

Given the similarities in reading rates, the iPad appears to be as effective as the currently used technologies within low-vision rehabilitation for improving reading rates at a substantially lower cost. While the CCTV is the current gold standard in low-vision rehabilitation, the cost $(\$ 2000$ CAD) makes the Apple iPad (\$549 CAD) a cheaper and more portable low-vision aid. While the iPad has some limitations in regards to the use of hard copy materials, its access to online resources, e-books, and apps targeted specifically for low-vision users makes the iPad a useful tool for those with visual impairments. Although our sample size is reasonable $(n=100)$, a larger sample is needed to conduct subgroup analyses on who would optimally benefit from tablet computer magnification in low vision. Yet based on the results presented here, it would appear that the iPad provides an alternative magnification device for individuals with low vision.

\section{Summary}

What was known before

- The iPad appears to increase reading speed, but it is unknown how the iPad compares to other low-vision rehabilitation devices.

What this study adds

- The Apple iPad significantly increases reading speed in participants with visual impairments. The Apple iPad improves reading speed at a comparable rate to the current gold standard in low-vision rehabilitation, the CCTV. Training on the Apple iPad may significantly increase reading speed compared to those who do not have training.

\section{Conflict of interest}

The authors declare no conflict of interest. 


\section{Acknowledgements}

This work was supported in part by the Vision Research Network, the Fonds de recherche du Québéc - Santé (\#28881, \#30620, and \#32643), the Antoine Turmel Foundation and the MAB-Mackay Foundation.

\section{References}

1 Pascolini D, Mariotti S. Global estimates of visual impairment: 2010. Br J Ophthalmol 2011; 96(5): 614-618.

2 United Nations, Department of Economic and Social Affairs, Population Division. World Population Prospects: The 2010 Revision. Vol. 1, Comprehensive Tables, 2011.

3 Blackmore-Wright S, Georgeson M, Anderson S. Enhanced text spacing improves reading performance in individuals with macular disease. PLoS One 2013; 8(11): e80325.

4 Rubin G. Measuring reading performance. Vis Res 2013; 90: 43-51.

5 Brown J, Goldstein J, Chan T, Massof R, Ramulu P. Characterizing functional complaints in patients seeking outpatient low-vision services in the United States. Ophthalmology 2014; 121(8): 1655-1662.e1.

6 Jutai J, Strong J, Russell-Minda E. Effectiveness of assistive technologies for low vision rehabilitation: a systematic review. J Vis Impair Blind 2009; 103(4): 210-222.

7 Zimmerman GJ, Zebehazy Kt, Moon ML. Optics and low vision devices. In: Corn A, Koenig A (eds). Foundations of Low Vision. AFB Press: New York, USA, 2010.

8 Robison S. Advanced glaucoma and low vision: evaluation and treatment. In: Schacknow P, Samples J (eds). The Glaucoma Book. Springer: New York, USA, 2010.

9 Nguyen N, Weismann M, Trauzettel-Klosinski S. Improvement of reading speed after providing of low vision aids in patients with age-related macular degeneration. Acta Ophthalmol 2009; 87(8): 849-853.

10 Mehr E, Frost A, Apple L. Experience with closed circuit television in the blind rehabilitation program of the veterans administration. Am J Optom Arch Am Acad Optom 1973; 50(6): 458-469.

11 Legge G, Mansfield J, Chung S. Psychophysics of reading: $X X$. Linking letter recognition to reading speed in central and peripheral vision. Vision Res 2001; 41(6): 725-743.

12 Cheong A, Lovie-Kitchin J, Bowers A. Determining magnification for reading with low vision. Clin Exp Optom 2002; 85(4): 229-237.

13 Crossland M, Silva RS, Macedo A. Smartphone, tablet computer and e-reader use by people with vision impairment. Ophthalmic Physiol Opt 2014; 34(5): 552-557.

14 Mann D. iPads May Help Those With 'Low Vision' Read Better. Available at: http://www.webmd.com/eye-health/news/ 20121108/ipads-may-help-those-with-low-vision-read-better (Accessed on 11 October 2015).
15 Gill K, Mao A, Powell A, Sheidow T. Digital reader vs print media: the role of digital technology in reading accuracy in age-related macular degeneration. Eye (Lond) 2013; 27(5): 639-643.

16 Roth DB, Feng HL, Fernandes A, Feuer W, Fine HF, Prenner JL. Electronic Reading Devices Increase Reading Speed and Comfort in Patients With Moderate Vision Loss. Poster session presented at: 116th Annual Meeting of the American Academy of Ophthalmology, 12-13 November 2012; Chicago, IL, USA.

17 Walker R, Bryan L, Harvey H, Riazi A, Anderson SJ. The value of Tablets as reading aids for individuals with central visual field loss: an evaluation of eccentric reading with static and scrolling text. Ophthalmic Physiol Opt 2016; 36: 459-464.

18 Rubin GS, Legge GE. Psychophysics of reading. VI-The role of contrast in low vision. Vision Res 1989; 29(1): 79-91.

19 Harland S, Legge GE, Luebker A. Psychophysics of reading. XVII. Low-vision performance with four types of electronically magnified text. Optom Vis Sci 1998; 75(3): 183-190.

20 Rubin GS, Turano K. Reading without saccadic eye movements. Vision Res 1992; 32(5): 895-902.

21 Regie de l'assurance maladie du Quebec/RAMQ. Services covered in Quebec - Visual devices. Available at: http://www. ramq.gouv.qc.ca/en/citizens/aid-programs/visual-aids/ Pages/visual-aids.aspx [Accessed on 11 January 2016].

22 Nasreddine Z, Phillips N, Bédirian V, Charbonneau S, Whitehead V, Collin I et al. The Montreal Cognitive Assessment, MoCA: a brief screening tool for mild cognitive impairment. J Am Geriatr Soc 2005; 53(4): 695-699.

23 Wittich W, Phillips N, Nasreddine Z, Howard C. Sensitivity and specificity of the montreal cognitive assessment modified for individuals who are visually impaired. $J$ Vis Impair Blind 2010; 106(4): 360-368.

24 Hart P, Chakravarthy U, Stevenson M, Jamison J. A vision specific functional index for use in patients with age related macular degeneration. Br J Ophthalmol 1999; 83(10): 1115-1120.

25 Trauzettel-Klosinski S, Dietz K. Standardized Assessment of Reading Performance: The New International Reading Speed Texts IReST. Invest Ophthalmol Vis Sci 2012; 53(9): 5452-5461.

26 Kline R. Beyond Significance Testing. American Psychological Association: Washington, DC, 2013.

27 Arthanat S, Vroman KG, Lysack C. A home-based individualized information communication technology training program for older adults: a demonstration of effectiveness and value. Disabil Rehabil Assist Technol 2016; 11(4): 316-324.

28 Hoeben F, den Brinker B. Nausea during reading with CCTV magnifiers: Relation with exposure time. In: Stuen C, Arditi A, Horowitz A, Lang AL, Rosenthal B, Seidman K (eds). Vision Rehabilitation - Assessment, Intervention and Outcomes. Lighthouse International: New York, USA, 2000; pp 329-332.

29 Walker R. An iPad app as a low-vision aid for people with macular disease. Br J Ophthalmol 2012; 97(1): 110-112. 